\title{
RESPON MASYARAKAT DESA MALANCAN TERHADAP IUPHHK-HA PT. SALAKI SUMMA SEJAHTERA (SSS) DI KECAMATAN SIBERUT UTARA KABUPATEN KEPULAUAN MENTAWAI
}

\author{
Vicky Trinaldi ${ }^{1}$ Endah Purwaningsih ${ }^{2}$ \\ Program Studi Geografi \\ Fakultas Ilmu Sosial Universitas Negeri Padang \\ email: vickytrinaldi@gmail.com
}

\begin{abstract}
ABSTRAK
Tujuan penelitian ini adalah untuk mengetahui bagaimana respon masyarakat Desa Malancan terhadap IUPHHK-HA PT. Salaki Summa Sejahtera (SSS) di Kecamatan Siberut Utara Kabupaten Kepulauan Mentawai. Peneltian ini merupakan penelitian kuantitatif dan kualitatif ( $m i x$ method). Jenis data yang digunakan adalah data primer. Ada 87 orang menjadi sampel responden peneltian yang berada di 6 dusun dari 9 dusun yang berada di Desa Malancan. Pengambilan data dengan cara menyebar angket dan dianalisis menggunakan skala likert. Hasil penelitian tentang karakteristik sosial demografi dengan jenis kelamin laki-laki adalah (78\%), kategori rentang umur 40-49 tahun (39\%), penduduk asli (93\%). Tingkat pendidikan rendah (42\% tidak sekolah). Pekerjaan sebagai petani atau berladang (90\%), pendapatan perbulan Rp.1.000.000-Rp.3.000.000 (60\%), kepemilikan lahan di area konsesi (86\% memiliki lahan). Respon masyarakat dengan kategori sikap -0,49 (negatif), respon dengan kategori partisipasi -0,60 (negatif), dan aspek keseluruhan -0,55 (negatf). Tanggapan masyarakat Desa Malancan cenderung menolak adanya perusahaan PT. SSS beroperasi karena masyarakat menganggap pengelolaan yang dilakukan oleh perusahaan kurang baik, mereka seolah-olah tidak memikirkan masyarakat yang berada dalam kawasan konsesi dan tidak adanya bantuan fisik maupun sosial kepada masyarakat.
\end{abstract}

\section{Kata kunci: Respon, Karakteristik, Perusahaan Kayu}

\section{ABSTRACT}

The purpose of this study was to find out how the response of the Malancan Village community to IUPHHK-HA PT. Salaki Summa Sejahtera (SSS) in North Siberut District, Mentawai Islands Regency. This research is quantitative and qualitative research (mix method). The type of data used is primary data. There were 87 people as samples of research respondents in 6 hamlets from 9 hamlets in Malancan Village. Data retrieval by distributing questionnaires and analyzed using a Likert scale. The results of the study on social demographic characteristics with male gender were (78\%), age range 40-49 years (39\%), native population (93\%). Education level is low (42\% are not in school). Work as a farmer or farmer (90\%), monthly income of Rp.1,000,000-Rp.3,000,000 (60\%), ownership of land in the concession area (86\% owning land). Community response with the attitude category of -0.49 (negative), response with participation categories -0.60 (negative), and overall aspects - 0.55 (negative). The response of the Malancan Village community tends to reject the existence of PT. SSS operates because the community considers that the management carried out by the company is not good, they do not seem to think about the community in the concession area and there is no physical or social assistance to the community.

Keywords: Response, Characteristics, Timber Companies

\footnotetext{
${ }^{1}$ Mahasiswa Jurusan Geografi

${ }^{2}$ Dosen Jurusan Geografi, Fakultas Ilmu Sosial, Universitas Negeri Padang, Pembimbing I
} 


\section{PENDAHULUAN}

Sektor kehutanan memiliki posisi yang sangat penting dalam struktur pembangunan di Indonesia karena peran ekonomi dan lingkungan yang dimainkannya menyentuh berbagai kepentingan kehidupan. Menurut Saragih (2001), hutan sangat berpengaruh di desa atau rakyat lokal. Pada masyarakat tradisional, hutan menjadi sumber kayu (kayu bakar dan bahan bangunan), sumber bahan obatobatan, sumber bahan makanan, dan penyediaan air. Oleh karena itu hutan sangat penting bagi masyarakat lokal, hutan harus dijaga kelestariannya melalui kelembagaan dan aturan lokal.

Penataan kawasan hutan di Indonesia mengacu pada kebijakan yang dikeluarkan oleh pemerintah dalam hal ini adalah Kementrian Kehutanan. Penetapan kawasan hutan di setiap provinsi di Indonesia diawali oleh Keputusan Menteri Pertanian Nomor 680/Kpts/Um/8/81 tentang Pedoman Penatagunaan Hutan Kesepatan didasari oleh kesepakatan antar instansi terkait dan antar pemerintah pusat dan pemerintah daerah yang menyangkut kawasan hutan dan non hutan yang dikenal dengan Tata Guna Hutan Kesepakatan.

Pengelolaan hutan merupakan salah satu bentuk memanfaatkan sumberdaya alam yang mempunyai arti penting bagi pembangunan perekonomian. sektor kehutanan merupakan penyumbang devisa terbesar kedua setelah minyak dan gas bumi. Dengan semakin berkembangnya teknologi dan semakin tingginya kebutuhan lahan untuk sector lain, sumberdaya hutan khususnya sebagai penghasil kayu semakin menurun, terutama pada hutan alam. Salah satu penyebabnya adalah semakin meningkatnya pemanfaatan sumberdaya hutan oleh pemerintah dan pemegang hak pengusahaan hutan (HPH) atau sekarang dikenal dengan Izin Usaha Pemanfaatan Hasil Hutan Kayu (IUPHHK).

Menurut Keputusan Menteri Kehutanan No.70/Kpts-II/2001 tentang Penetapan Kawasan Hutan, perubahan status dan fungsi kawasan hutan, yaitu wilayah tertentu yang ditetapkan oleh pemerintah untuk difungsikan sebagai hutan tetap. Dari definisi dan penjelasan tentang kawasan hutan, terdapat unsur-unsur meliputi:

a. Suatu wilayah tertentu

b. Terdapat hutan atau tidak terdapat hutan

c. Ditetapkan oleh pemerintah (menteri) sebagai kawasan hutan

d. Didasarkan pada kebutuhan serta kepentingan masyarakat

Hutan Mentawai sudah di eksploitasi sejak tahun 1970-an yang diawali lahirnya UU no. 5 tahun

\footnotetext{
${ }^{1}$ Mahasiswa Jurusan Geografi

${ }^{2}$ Dosen Jurusan Geografi, Fakultas Ilmu Sosial, Universitas Negeri Padang, Pembimbing I
} 
1967 tentang ketentuan pokok kehutanan yang menetapkan tiga perempat dari luas lahan di Indonesia salah satunya Mentawai masuk dalam penetapan kawasan hutan tersebut. Pada tahun 2001 PT. KAM mulai memanfaatkan hasil kayu di Kepulauan Mentawai namun hanya bertahan sampai tahun 2007 padahal mempunyai izin sampai 2046, kemudian lahan bekas PT. KAM tersebut dijadikan kawasan Restorasi Ekosistem berdasarkan pada SK Menhut No. 423/Menhut-II/2009 pada 14 Juli 2009 yang mempunyai luas 79.795 ha untuk PT. Global Green namun sampai ssat ini perusahaan tersebut belum beroperasi. Pada saat ini ada dua perusahaan kayu yang beroperasi di Kepulauan Mentawai yaitu PT. Minas Pagai Lumber (MPL) seluas 78.000 ha di Pulau Pagai UtaraPagai Selatan dan PT. Salaki Summa Sejahtera (SSS) di Pulau Siberut seluas 49.440 ha.

Perusahaaan kayu yang beroperasi saat ini yaitu PT. SSS yang berada di utara Pulau Siberut Kabupaten Kepulauan Mentawai mendapatkan izin dari pemerintah pada tahun 2004 yang merupakan metamorfosa dari PT. Tjirebon Agung lewat izin HPH/IUPHHK seluas 70.000 hektar pada tahun 1970 dan pada tahun 2001 PT. SSS mendapat izin persetujuan AMDAL dengan keluarnya SK No. 105/KptsII/2001 tanggal 15 maret 2001 seluas 49.440 hektar (12,3 \% Pulau Siberut) dan pada tahun 2008 perusahaan tersebut resmi beroperasi. Kawasan konsesi PT. SSS bertumpang tindih dengan wilayah permukiman masyarakat dan tanah ulayat adat Desa Sigapokna, Malancan, Mongan Poula, Sikabaluan dan desa lain di Siberut Utara.

Desa Malancan merupakan wilayah administrasi desa yang berada dalam konsesi PT. SSS, sehingga banyak tanah ulayat masyarakat bertumpang tindih dengan kawasan konsesi perusahaan kayu tersebut sehingga menimbulkan berbagai konflik antara masyarakat Malancan dengan pihak PT. SSS.

Sebelum izin dikeluarkan untuk PT. SSS masyarakat Siberut Utara sudah menolak adanya eksploitasi terhadap hutan di Mentawai karena rencana wilayah konsesi PT. SSS terdapat di wilayah permukiman dan lahan warga sehingga mereka menolak adanya perusahaan tersebut (Pualiggoubat, no 43, 1-14 Maret 2004, hal 3). Selain itu masyarakat juga menolak karena beralasan Mentawai khususnya Siberut Utara rawan adanya bencana alam seperti terjadinya longsor, banjir bandang karena daya dukung ekologinya sangat terbatas.

Masyarakat Malancan yang bergantung terhadap hasil hutan dengan mengolah lahan yang telah mereka miliki sejak nenek moyang 
mereka kemudian diusik karena adanya izin IUPHHK-HA sehingga masyarakat pada dasarnya lebih banyak menolak kehadiran PT. SSS dan dengan melihat Peraturan Menteri Lingkungan Hidup dan Kehutanan No. 24 Tahun 2016 Pasal 4 ayat 1 menyatakan bahwa penggunaan kawasan hutan untuk kepentingan pembangunan di luar kegiatan kehutanan hanya dapat dilakukan untuk kegiatan yang mempunyai tujuan yang strategis yang tidak dapat dielakkan, seperti kegiatan religi, pertambangan, jalan umum, pertanian tertentu dalam rangka ketahanan pangan, dll. Kawasan permukiman dan lahan warga tidak seharusnya ada dalam kawasan konsesi perusahaan tersebut. Adanya terjadi konflik antara msyarakat dengan perusahaan seperti kasus masyarakat memblokade jalan milik PT Salaki Summa Sejahtera karena perusahaan tidak membayarkan fee kayu (biaya yang diberikan kepada masyarakat oleh perusahaan) terhadap masyarakat. Berdasarkan observasi awal peneliti mendapatkan informasi adanya masyarakat yang setuju dan tidak setuju dengan PT. SSS di Desa Malancan.

Penelitian ini berbeda dari penelitian yang dilakukan oleh peneliti sebelumnya. Penelitian ini bertujuan untuk mengetahui respon masyarakat Desa Malancan terhadap PT. SSS di Kecamatan Siberut Utara Kabupaten Kepulauan Mentawai.
Adapun penelitian sebelumnya dilakukan oleh Mario Vanricho (2015) dengan judul penelitian Respon Masyarakat Terhadap Kehadiran PT. Sarulla Operation LTD (SOL) di Kecamatan Pahae Julu Kabupaten Tapanuli Utara dan penelitian Davindra Dirgantara (2018) dengan judul Persepsi Masyarakat Tentang Rencana Pembangunan PLTP Gunung Talang-Bukit Kili di Kabupaten Solok.

\section{METODE PENELITIAN}

Penelitian ini tergolong tipe penelitian menggunakan pendekatan deskriptif, yaitu penelitian yang dilakukan dengan tujuan menggambarkan atau mendeskripsikan objek dan fenomena yang diteliti. Penelitian ini menggunakan metode kuantitatif dan kualitatif (mix methods) dengan menjabarkan hasil penelitian sebagaimana adanya data yang diperoleh di lapangan, dikumpulkan, diolah serta dianalisis. Metode kuantitatif digunakan untuk menghitung respon masyarakat, metode kualitatif digunakan untuk melihat tanggapan masyarakat tentang IUPHHK-HA PT. Salaki Summa Sejahtera. Melalui penelitian ini penulis menggambarkan tentang bagaimana respon masyarakat Desa Malancan terhadap IUPHHK-HA PT. Salaki Summa Sejahtera (SSS) di Kecamatan Siberut Utara Kabupaten Kepulauan Mentawai. 
Jenis data dalam penelitian ini adalah data primer yang menggunakan teknik purposive sample, adapun menjadi populasi dalam data tersebut adalah masyarakat Desa Malancan yang diwakili oleh 6 (enam) dusun dari 9 (sembilan) dusun yang berjumlah 200 KK, kemudian didapatkan sampel sebanyak 87 orang responden menggunakan rumus Slovin.

Teknik analisis data dengan cara mengumpulkan data dari hasil kuesioner (angket), wawancara kemudian ditabulasi dalam bentuk distribusi frekuensi dan kemudian dianalisis.

\section{Cara}

merumuskan

kesimpulan hasil penelitian, khususnya mengindentifikasi respon, penulis menggunakan hasil penghitungan dari kuesioner digunakan untuk mengukur sikap dan partisipasi responden. Subjek penelitian ini dihadapkan pada pernyataan positif dan negatif melalui pernyataan setuju, kurang setuju dan tidak setuju.

Pemberian skor data dilakukan mulai respon yang negatif menuju respon yang positif, yakni :
a. Skor Negatif adalah -1
b. Skor Netral adalah 0
c. Skor Positif adalah 1

Sebelum menentukan klasifikasi sikap dan partisipasi maka ditentukanlah interval kelas sebagai pengukuran, yaitu :

$$
\begin{aligned}
& \text { Interval kelas }(i) \\
& =\frac{\text { nilai tertinggi }(H)-\text { nilai terendah }(L)}{\text { banyak kelas }(K)} \\
& =\frac{1-(-1)}{2} \\
& =\frac{2}{2} \\
& =1
\end{aligned}
$$

Maka untuk menentukan katagori respon positif, netral maupun respon negatif maka digambarkan nilai batasan sebagai berikut:

Tabel 1. Kategori Respon

\begin{tabular}{ll}
\hline & -1.00 \\
0,33
\end{tabular}

2. $-0,33$ sampai dengan 0,33 Respon Netral

3. 0,33 sampai dengan $1 \quad$ Respon Positif

Sumber : Sugiyono, 2014

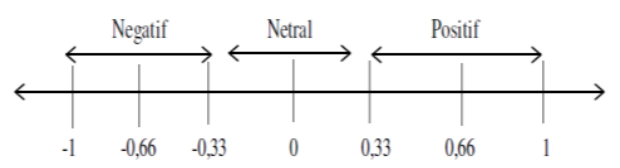

Penelitian dilakukan kepada 87 orang responden masyarakat yang berada di 6 (enam) Dusun dari 9 (sembilan) dusun yang ada di Desa Malancan, Kecamatan Siberut Utara, Kabupaten Kepulauan Mentawai. Dusun yang menjadi sampel wilayah penelitian adalah Dusun Sinaki 12 responden, Dusun Malancan 17 responden, Dusun Ukra 16 
responden, Dusun Sirilanggai 13 responden, Dusun Sibeotcun 15 responden, Dusun Terekan Hulu 14 responden. Teknik analisis data digunakan untuk menghitung sikap dengan indikator tanggapan responden hasil dari rekapitulasi kuesioner penelitian. Berikut deskripsi kuesioner penelitian responden masyarakat Desa Malancan terhadap adanya PT. Salaki Summa Sejahtera dari aspek sikap (soal 1-4) dan aspek partisipasi (soal 5-8).

\section{Sikap Responden Terhadap Adanya PT. SSS di Desa Malancan}

Pemberian skor kategori sikap responden terhadap adanya PT. SSS merupakan kategori awal dalam mengukur respon. Hasil skor sikap (V1) merupakan hasil rata-rata $\Sigma$ skor kategori sikap : (Hasil jumlah pertanyaan/sub kategori $\times$ Jumlah Responden).

$V 1=$

$\frac{\text { Hasil jumlah pertanyaan }}{\text { sub kategori }} \times$ Jumlah Responden.

Jumlah sub kategori sikap ada 4 (empat) sub variabel sehingga ratarata $\mathrm{V} 1=\Sigma$ skor kategori : $(4 \times 87)$.

Mengetahui apakah sikap masyarakat terhadap adanya PT. SSS di Desa Malancan termasuk respon positif, netral atau negatif maka dilakukan analisis dengan memberikan nilai 1 pada respon positif, nilai 0 pada respon netral dan nilai -1 pada respon negatif lalu dibagi dengan jumlah responden.

Hasil akhir dapat dilihat apakah positif, netral atau negatif dengan adanya batasan nilai pada skala likert, yaitu sebagai berikut:

$$
\begin{aligned}
& =-172:(4 \times 87) \\
& =-172: 348 \\
& =-0,49
\end{aligned}
$$

Keterangan :

$\Sigma$ skor kategori Sikap $\quad=-172$

Jumlah sub kategori Sikap $\quad=4$

Jumlah responden $\quad=87$

Hasil kategori Sikap $\quad=-0,49$

Berdasarkan hasil dari skala likert tersebut, maka dapat diketahui bahwa responden memiliki sikap "Negatif" dengan hasil skor: $-0,49$ karena berada di antara -1 sampai dengan -0,33. Jadi, responden memiliki sikap negatif terhadap kehadiran PT. Salaki Summa Sejahtera (SSS) di Desa Malancan Kecamatan Siberut Utara Kabupaten Kepulauan Mentawai.

\section{Partisipasi Responden Terhadap PT. SSS Di Desa Malancan}

Pemberian skor kategori sikap responden terhadap adanya PT. SSS merupakan kategori awal dalam mengukur respon. Hasil skor sikap (V2) merupakan hasil rata-rata $\Sigma$ skor kategori sikap : (Hasil jumlah pertanyaan/sub kategori $\times$ Jumlah Responden) 
. $V 1=$

$\frac{\text { Hasil jumlah pertanyaan }}{\text { sub kategori }} \times$ Jumlah Responden.

Jumlah sub kategori sikap ada 4 (empat) sub variabel sehingga rata-rata $\mathrm{V} 2=\Sigma$ skor kategori : $(4 \times 87)$.

Mengetahui apakah sikap masyarakat terhadap adanya PT. SSS di Desa Malancan termasuk respon positif, netral atau negatif maka dilakukan analisis dengan memberikan nilai 1 pada respon positif, nilai 0 pada respon netral dan nilai -1 pada respon negatif lalu dibagi dengan jumlah responden.

Hasil akhir dapat dilihat apakah positif, netral atau negatif dengan adanya batasan nilai pada skala likert, yaitu sebagai berikut:

$$
\begin{aligned}
& =-210:(4 \times 87) \\
& =-210: 348 \\
& =-0,60
\end{aligned}
$$

Keterangan :

$\begin{array}{ll}\Sigma \text { skor kategori Partisipasi } & =-210 \\ \text { Jumlah sub kategori Partisipasi } & =4 \\ \text { Jumlah responden } & =87 \\ \text { Hasil kategori Partisipasi } & =-0,60\end{array}$

Berdasarkan hasil dari skala

likert tersebut, maka dapat diketahui bahwa responden memiliki sikap "Negatif" dengan hasil skor: $-0,60$ karena berada di antara -1 sampai dengan -0,33. Jadi, responden memiliki partisipasi negatif terhadap kehadiran PT. Salaki Summa Sejahtera (SSS) di Desa Malancan
Kecamatan Siberut Utara Kabupaten Kepulauan Mentawai.

\section{Tanggapan Secara Keseluruhan}

Pada tanggapan keseluruhan penulis akan menganalisis tanggapan secara menyeluruh terhadap aspek sikap dan partisipasi. Pemberian skor kategori keseluruhan responden terhadap adanya PT. SSS merupakan kategori ketiga dalam mengukur respon. Hasil skor sikap (V3) merupakan hasil rata-rata $\Sigma$ skor kategori sikap : (Hasil jumlah pertanyaan/sub kategori $\times$ Jumlah Responden).

$V 1=$

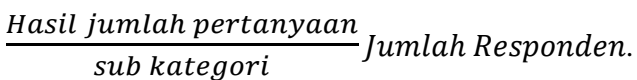

Jumlah sub kategori sikap ada 4 (empat) sub variabel sehingga ratarata V3 $=\Sigma$ skor kategori : $(8 \times 87)$.

Mengetahui apakah sikap masyarakat terhadap adanya PT. SSS di Desa Malancan termasuk respon positif, netral atau negatif maka dilakukan analisis dengan memberikan nilai 1 pada respon positif, nilai 0 pada respon netral dan nilai -1 pada respon negatif lalu dibagi dengan jumlah responden.

Hasil akhir dapat dilihat apakah positif, netral atau negatif dengan adanya batasan nilai pada skala likert, yaitu sebagai berikut:

$$
\begin{aligned}
& =-381:(8 \times 87) \\
& =-381: 696 \\
& =-0,55
\end{aligned}
$$


Keterangan :

$\Sigma$ skor kategori Keseluruhan = 381

Jumlah sub kategori Keseluruhan $=8$

Jumlah responden $\quad=87$

Hasil kategori Keseluruhan =-

0,55

Berdasarkan hasil dari skala likert tersebut, maka dapat diketahui bahwa responden memiliki respon "Negatif" dengan hasil skor: -0,55 karena berada di antara -1 sampai dengan -0,33. Jadi, responden memiliki respon negatif terhadap kehadiran PT. Salaki Summa Sejahtera (SSS) di Desa Malancan Kecamatan Siberut Utara Kabupaten Kepulauan Mentawai.

Cara memperoleh hasil dari penelitian kualitatif tentang tanggapan responden digunakan hasil wawancara dengan menggunakan kuesioner terbuka, jadi untuk kesimpulan dari penelitian ini peneliti menghubungkan sikap, partisipasi yang diperoleh dari metode kuantitatif dan tanggapan responden dengan metode kualitatif tentang PT. Salaki Summa Sejahtera (SSS).

\section{HASIL DAN PEMBAHASAN}

\section{Karakteristik Sosial Demografi}

a. Jenis Kelamin

Berdasarkan

responden masyarakat Desa Malancan 68 orang (78\%) berjenis kelamin laki-laki, 19 (22\%) orang berjenis kelamin perempuan. b. Umur

Tingkatan klasifikasi
rentang umur responden
masyarakat Desa Malancan,
dimana rentang umur paling
banyak pada 40-49 tahun
dengan frekuensi 34 orang
(39\%), rentang umur 50-59
tahun dengan frekuensi 22
orang (25\%), rentang umur
$30-39$ tahun dengan frekuensi
20 orang (23\%), rentang umur
$>60$ tahun dengan frekuensi 8
orang (8\%), rentang umur 20-
29 tahun dengan frekuensi 3
orang (5\%) dan rentang umur
$10-19$ tahun dengan frekuensi
0 orang
Asal
Sebanyak 81
(93\%) adalah pribumi asli
Desa Malancan dan sebanyak 6 orang $(7 \%)$ adalah masyarakat non-pribumi Desa Malancan.

\section{Tingkat Pendidikan Responden}

Masyarakat Desa Malancan yang tidak mengenyam bangku pendidikan atau tidak sekolah yaitu 37 orang (42\%), sebanyak 27 orang $(32 \%)$ tingkat pendidikan SD/Sederajat, 12 orang (14\%) tingkat pendidikan SMP/Sederajat, 8 orang $(9 \%)$ tingkat pendidikan SMA/Sederajat dan 3 orang (3\%) yang menempuh perguruan tinggi.

3. Karakteristik

Ekonomi

\section{Responden}


a. Pekerjaan

Sebanyak 87 orrang menjadi sampel di Desa Malancan 78 orang (90\%) responden mempunyai pekerjaan sebagai petani, bekerja sebagai Pegawai Negeri Sipil (PNS) sebanyak 5 orang $(6 \%), 3$ orang $(3 \%)$ responden bekerja sebagai wiraswasta dan pekerjaan diluar petani, wiraswasta dan PNS (dan lain-lain) 1 orang (1\%).

b. Pendapatan

Sebanyak 52 orang (60\%) mempunyai pendapatan per bulan berkisar antara Rp. 1000.000 - Rp. 3.000.000, 27 orang (31\%) responden memiliki pendapatan < Rp. 1.000.000, 8 orang (9\%) memiliki pendapatan Rp. 3.000.000 - Rp. 5.000.000 dan tidak ada masyarakat yang mempunyai pendapatan di atas Rp. 5.000.000.

c. Kepemilikan Lahan

Sebanyak 87 responden masyarakat Desa Malancan 75 orang (86\%) responden memiliki lahan di area konsesi PT. SSS dan 12 orang (14\%) responden tidak mempunyai lahan di area konsesi PT. SSS tersebut.

\section{Respon Masyarakat}

Tabel 2. Rekapitulasi Data Respon Masyarakat

\begin{tabular}{cccc}
\multicolumn{3}{c}{ Masyarakat } \\
\hline & & & \\
\hline & & & \\
& & & Tidak \\
& & & Setuju \\
& & & \\
\hline 1 & $17 \%$ & $15 \%$ & $68 \%$ \\
\hline 2 & $2 \%$ & $78 \%$ & $20 \%$ \\
\hline 3 & $2 \%$ & $10 \%$ & $88 \%$ \\
\hline 4 & $8 \%$ & $16 \%$ & $76 \%$ \\
\hline 5 & $9 \%$ & $18 \%$ & $73 \%$ \\
\hline 6 & $15 \%$ & $14 \%$ & $71 \%$ \\
\hline 7 & $15 \%$ & $6 \%$ & $79 \%$ \\
\hline 8 & $14 \%$ & $5 \%$ & $81 \%$ \\
\hline
\end{tabular}

Sumber: Pengolahan Data Tahun 2019

Berdasarkan tabel di atas terlihat semua jawaban dari soal menunjukan pernsetase paling besar pada opsi jawaban tidak setuju, dapat disimpulkan bahwa masyarakat Desa Malancan Tidak setuju jika PT. SSS beroperasi di sana.

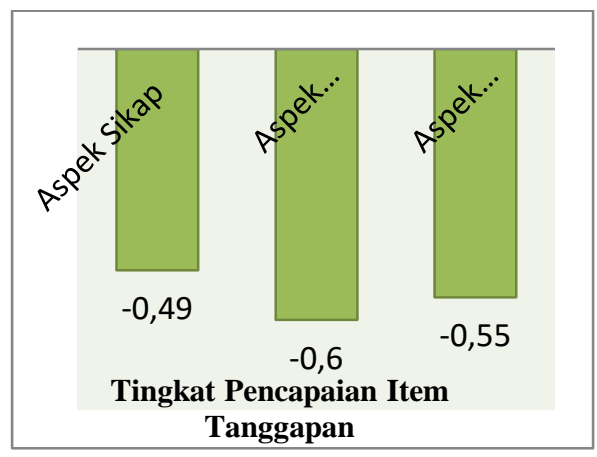

Gambar 1. Tingkat Pencapaian Item Tanggapan

Dalam penghitungan yang dilakukan menggunakan rumus dan skala likert menurut klasifikasi Sugiyono, di dapat hasil respon masyarakat Desa Malancan terhadap adanya PT. Saaki Summa Sejahtera 
pada aspek sikap $-0,49$ dimana menurut kalsifikasi respon menunjukan pada sikap "negatif", pada aspek partisipasi -0,60 dimana menurut klasifikasi respon menunjukan pada sikap "negatif", kemudian aspek keseluruhan -0,55 dimana menurut klasifikasi respon menunjukkan pada sikap "negatif".

\section{Hasil Wawancara}

Kesimpulan dari wawancara yang dilakukan terhadap responden menjukan bagaimana sikap responden yang lebih cenderung menolak karena berbagai alasan diantaranya sebagai berikut:

a. Adanya tumpang tindih lahan masyarakat dengan kawasan konsesi sehingga ruang gerak masayarakat menjadi terbatas untuk melakukan kegiatan pertanian maupun perladangan.

b. Pengelolaan koperasi yang kurang baik dibentuk oleh perusahaan sebagai lembaga pembayaran fee kayu terhadap masyarakat sehingga membuat masyarakat memiliki merasa tidak diuntungkan dalam pengambilan kayu yang berada di tanah mereka.

c. perusahaan seolah acuh karena jarang memberikan bantuan sosial maupun fisik kepada masyarakat.
Kemudian perusahaan tidak pernah melibatkan masyarakat sehingga tidak ada pastisipasi masyarakat kepada perusahaan sebagai contoh masyarakat tidak pernah merawat sarana dan prasarana perusahaan karena tidak adanya sarana dan prasarana yang diberikan oleh perusahaan kepada masyarakat.

Pada dasarnya masyarakat Desa Malancan menolak adanya PT. SSS beroperasi di desa mereka karena tanahnya bertumpang tindih dengan perusahaan sehingga masyarakat berupaya untuk mengeluarkan tanah mereka dari kawasan konsesi PT. SSS. Langkah yang di lakukan masyarakat adalah dengan memetakan tanah ulayat tersebut dengan melakukan kerja sama dengan Lembaga Swadaya Masyarakat (LSM) yaitu Yayasan Citra Mandiri Mentawai (YCMM) sebagai fasilitator untuk pemetaan tersebut, upaya ini dilakukan karena tanah tersebut telah turun menurun dari nenek moyang mereka jauh sebelum adanya perusahaan tersebut di sana.

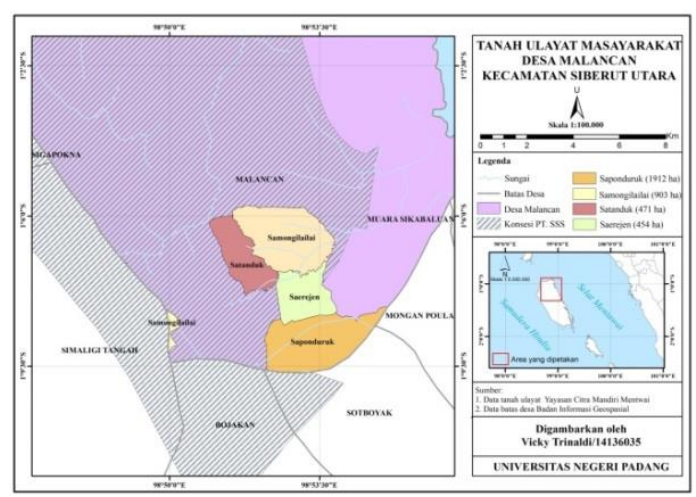

Gambar 2. Peta Tanah Ulayat Masyarakat di Desa Malancan 
Berdasarkan peta tersebut terlihat masyarakat sudah melakukan usaha untuk mengeluarkan tanah ulayat mereka dari kawasan konsesi PT. SSS, masyarakat bekerjasama dengan Yayasan Citra Mandiri Mentawai (YCMM) untuk menjadi fasilitator dalam memetakan tanah mereka. Sudah ada 4 (empat) suku yang sudah melakukan pemetaan tanah ulayat yaitu Suku Saerejen (454 ha), Suku Satanduk (471 ha), Suku Samongilailai (903 ha), dan Suku Saponduruk (1.912 ha). Berdasarkan putusan MK No. 35/PUU-X/2012 mengatakan kawasan hutan adat bukan hutan Negara yang membuat hutan adat diakui oleh Negara tapi tidak merubah fungsi hutan tersebut. Maka dari itu masyarakat berupaya untuk mengambil hak mereka kembali dengan usaha memetakan tanah ulayat tersebut walaupun prosesnya begitu lama.

\section{PENUTUP}

\section{Kesimpulan}

Berdasarkan data yang telah penulis olah maka dapat disimpulkan bahwa respon masyarakat Desa Malancan menurut sikap, partisipasi dan aspek keseluruhan.

a. Sikap, dari 87 orang masyarakat Desa Malancan memiliki sikap "negatif" terhadap PT. Salaki Summa Sejahtera (SSS) dengan nilai $-0,49$. Pengukuran sikap ini dilihat dengan tanggapan responden yang tidak setuju terhadap PT. Salaki Summa Sejahtera.

b. Partisipasi, dari 87 orang masyarakat Desa Malancan menunjukan partisipasi "negatif" dengan nilai $-0,60$. Pengukuran ini dilihat dari tidak adanya masyarakat terlibat dalam program serta memberikan saran terhadap PT. Salaki Summa Sejahtera (SSS).

c. Secara keseluruhan, berdasarkan dari kedua variabel tersebut respon masyarakat Desa Malancan terhadap PT. Salaki Summa Sejahtera (SSS) adalah "negatif" dengan nilai $-0,55$ (berada antara -1 sampai dengan 0,33). Dengan demikian dapat disimpulkan bahwa respon masyarakat Desa Malancan terhadap IUPHHK-HA PT. Salaki Summa Sejahtera (SSS) adalah "negatif".

\section{Saran}

Berdasarkan kesimpulan penelitian di atas, peneliti menyampaikan sedikit saran yang diharapkan berguna untuk kepentingan bersama, saran yang disampaikan adalah sebagai berikut:

1. Dengan melihat usia masyarakat produktif dan pribumi lebih banyak, PT. Salaki Summa Sejahtera (SSS) harus memberikan peluang kerja terhadap masyarakat sehingga bisa membantu perekonomian masyarakat. 
2. Kepada PT. Salaki Summa Sejahtera (SSS) untuk lebih membaur dengan masyarakat agar keluhan dan saran masyarakat dapat di terima sebagai evaluasi demi kepentingan bersama.

3. Diharapkan kepada pemerintah agar melakukan pemetaan ulang untuk penetapan kawasan hutan agar tidak terjadi lagi tumpang tindih lahan yang dapat merugikan masyarakat karena masyarakat sangant bergantung pada lahan mereka sebagai sumber perekonomian mereka.

4. Kepada masyarakat Desa Malancan lebih banyak memberikan saran atau masukan kepada PT. Salaki Summa Sejahtera (SSS) mengenai program kerja yang mereka lakukan, kemudian segera memetakan tanah ulayat yang berada dalam area konsesi PT. Salaki Summa Sejahtera agar segera mungkin dapat dikeluarkan dari area tersebut.

\section{DAFTAR PUSTAKA}

Bungin, Burhan. 2013. Metodologi Penelitian Sosial dan Ekonomi: Format-Format Kuantitatif dan Kualitatif untuk Studi Sosiologi, Kebijakan, Publik, Komunikasi, Manajemen dan Pemasaran. Jakarta: Kencana.
Djurip. 2000. Tata Krama di Lingkungan Suku Mentawai. Padang: PD. Syukri.
MarioVanricho. 2015. "Respon Masyarakat Terhadap Kehadiran PT. Sarulla Operation LTD (SOL) di Kecamatan Pahae Julu Kabupaten Tapanuli Utara". Skripsi. Fakultas Ilmu Sosial dan Ilmu Politik USU. Medan.

Peraturan Menteri Lingkungan Hidup dan Kehutanan No. 24 Tahun 2010 tentang Penggunaan Kawasan Hutan.

Peraturan Menteri Kehutanan No. 41 Tahun 2014 tentang Kawasan Hutan.

Pinda Tangkas Simanjuntak. 2017. "Konflik Lahan Samongilailai di Desa Malancan, Siberut Utara". www.mentawaikita.com, diakses tanggal 15 Agustus 2018.

Saragih, B. 2001. Suara dari Bogor: Membangun Sistem Agribisnis, USESE dan SUCUFINDO. Bogor.

Sugiyono. 2014. Metode Penelitian Kuantitatif Kualitatif dan $R \& D$.Bandung 